Waidulla N Al-Âni

$\mathrm{BSc}, \mathrm{PhD}$ (Asst. Prof.)

Nahla O M Tawfik

$\mathrm{MBChB}, \mathrm{MSc}, \mathrm{PhD}$ (Lec.)

Enas Y Shehab

BSc, MSc (Asst. Lec.)

\section{Antimicrobial Activity of Grapefruit Seeds Extracts (In vitro Study)}

\author{
Department of Dental Basic Sciences \\ College of Dentistry, University of Mosul \\ Department of Dental Basic Sciences \\ College of Dentistry, University of Mosul \\ Department of Dental Basic Sciences \\ College of Dentistry, University of Mosul
}

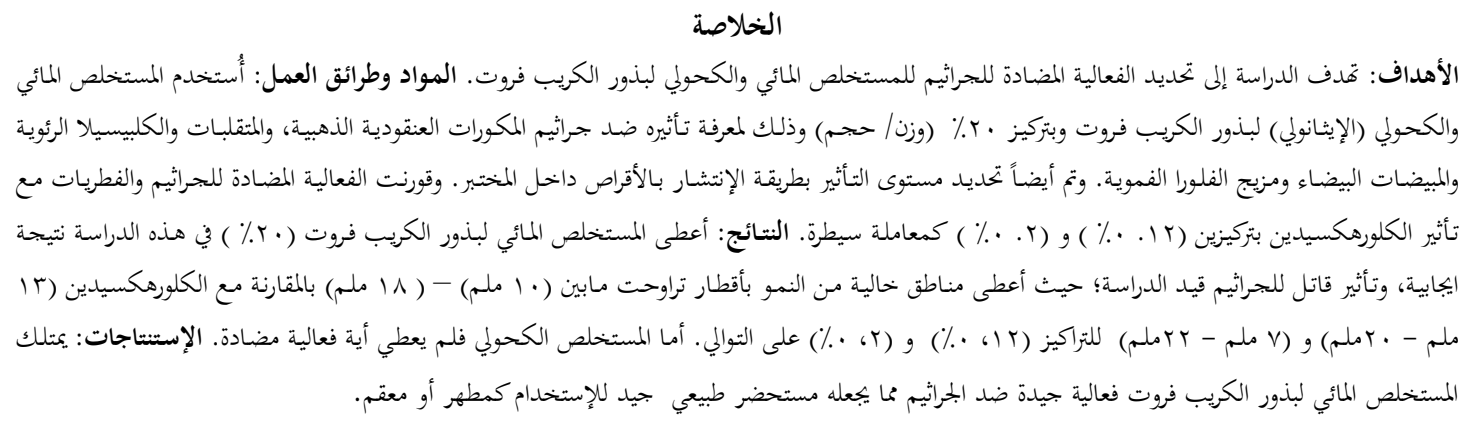

ABSTRACT

Aims: The purpose of this study is to determine the antimicrobial activity of aqueous and alcoholic extract of grapefruit (Citrus Paradisi Rutaceae) seeds. Materials and Methods: Aqueous and alcoholic (ethanol) extracts of grapefruit seeds "GSE" in $20 \%(\mathrm{w} / \mathrm{v})$ concentration were investigated for activity against Staphylococcus aureus, Proteus vulgaris, Klebsiella pneumonia, Candida albicans and a mixed oral flora. The level of antimicrobial effects was established using in vitro disc diffusion method. Their antibacterial and antifungal activity was compared to the activity of Chlorhexidine (CHX) solution in two concentrations ( 0.12 and $0.2 \%)$ as a control. Results: The aqueous GSE (20\%) solution used in this study gave positive results with lethal effect on the tested organisms with zones of inhibition ranging from $10 \mathrm{~mm}-18 \mathrm{~mm}$ in diameter, which is comparable to that of chlorhexidine $(7 \mathrm{~mm}-22 \mathrm{~mm})$ and (13mm - 20mm) for $0.12 \%$ and $0.2 \%$ solutions respectively. Ethanolic GSE did not show any antimicrobial activity. Conclusions: Aqueous GSE has a good antimicrobial effect, which makes it a good natural preparation for use as antiseptic or disinfectant.

Key Words: Grapefruit Seeds. chlorhexidine and aqueous extract.

Al-Âni WN, Tawfik NO, Shehab EY. Antimicrobial Activity of Grapefruit Seeds Extracts (In vitro Study) Al-Rafidain Dent J. 2011 11(2): 341-345.

Received: 16/5/2010 Sent to Referees: $16 / 5 / 2010$

Accepted for Publication: 28/6/2010

INTRODUCTION

The use of herbal medicine is widely spread and growing ${ }^{(1)}$. Plants have been exploited for the treatment of many infections and diseases because those plants readily contain substances for defense against attacks by insects, herbivores and microorganisms ${ }^{(2)}$. The citrus fruits make a group of plants of great medicinal importance ${ }^{(3)}$. The therapeutic efficacy of citrus fruits such as grape fruits is support- ed by the facts that they contain different classes of polyphenolic flavenoids that have been shown to exert antibacterial, antifungal and antioxidant activities $(4,5)$. Grapefruit seed extract (GSE) is a commercial product derived from the seeds and pulp of grapefruit ${ }^{(6,7)}$. The present study contributes to the identification of the antibacterial and antifungal effects of the self - made aqueous and ethanolic extracts of GSs and to compare those effects 
with an important orally used antiseptics solution chlorhexidine gluconate (CHX) in $0.12 \%$ and $0.2 \%$ concentrations.

\section{MATERIALS AND METHODS}

1. Preparation seeds for extraction: The seeds of the grape fruits were air-dried for two weeks to prevent loss of active components. Then were ground into powder with electrical blender. Water and ethanol alcohol were used for the extraction (8).

2. Preparation of aqueous extract:

Forty grams of dry seeds powder were placed in $160 \mathrm{ml}$ of sterile distilled water and left at room temperature for $24 \mathrm{hrs}$, the mixture was filtered firstly by gauze and secondly by filter paper (Whatman No. 1). After filtration, it was placed into incubator at $37 \mathrm{C}^{\circ}$. The liquid was evaporated, and the precipitated extract was left at the base of the baker ${ }^{(9)}$.

\section{Sterilization of aqueous extract:}

Five ml of distilled water was added to 1 gram of plant extract powder to produce $200 \mathrm{mg} / \mathrm{ml}(20 \% \mathrm{w} / \mathrm{v})$ solution, sterilization was carried out by passing through a sterile filter membrane $0.22 \mu \mathrm{g}^{(10)}$.

4. Preparation of alcoholic extract:

Twenty grams of dry seeds powder was added to $200 \mathrm{ml}$ of ethanol. The same procedure as in aqueous extract was appliedbut the solvent for extraction was $95 \%$ ethanol ${ }^{(9)}$.

5. Sterilization of alcoholic extract:

Five $\mathrm{ml}$ of Dimethyl sulfoxide was added to $1 \mathrm{gm}$ of seed extract powder and sterilized by pasteurization. The same concentration of $(20 \% \mathrm{w} / \mathrm{v})$ is as aqueous extract (10).

6. Sensitivity test (disc diffusion method): Susceptibility testing was done on each isolate (in triplicate) for each type of the extract, CHX solution ( 0.12 and $0.2 \%$ ) were used as control using disc diffusion method $^{(11)}$. Discs were prepared by adding $1 \mathrm{ml}$ of seed extract to 10 discs ${ }^{(12)}$.

Four types of bacterial isolates were used; Staphylococcus aureus, Proteus vulgaris, Klebsiella pneumonia and a mixed oral flora. The antifungal activity was test- ed against one fungal isolates (Candida albicans) by the disc diffusion method.

Colonies were streaked on MullerHinton agar. Within 15 minutes after the plates were inoculated, a prepared discs were applied to the surface of the inoculated plates by sterile forceps, taking care that each disc is $15 \mathrm{~mm}$ apart from edge of the plate. Then plates were placed in an incubator at $37 \mathrm{C}$ for 24 hours for bacteria and for 48 hours for Candida albicans ${ }^{(13)}$.

After incubation, the plates were examined, the zone of inhibition of growth were noted and measured. The antimicrobial activity of each extract was measured from the diameters of zone of inhibition for each organism and this was compared with that of $\mathrm{CHX}$ solution $(0.12 \%$ and $0.2 \%)$.

\section{RESULTS}

The antimicrobial effects of self made $20 \%$ (w/v) GSE (aqueous and ethanolic) extracts and CHX solution $(0.12 \%$ and $0.2 \%$ ) are shown in Table (1).

The ethanolic extract showed no zone of inhibition. The aqueous extract (20\%) was active against all gram negative bacteria (Figure, 1). GSE produced the largest zone of inhibition for normal flora (18mm) (Table, 1), but exerted lower activity on the growth of Staphylococcus aureus (10mm). In comparison, CHX $0.2 \%$ (control I) showed the largest zone of inhibition against normal flora $(20 \mathrm{~mm})$, while exerted lower activity on the growth of $S$. aureus, Proteus sp. and Klebsiella $s p$ (18mm). The zone of inhibition to CHX $0.12 \%$ (control II) is 7, 11, 18 and $22 \mathrm{~mm}$ for S. aureus, Proteus sp., Klebsiella sp, and normal flora respectively. The aqueous extract (20\%) was active against Candida albicans with a zone of inhibition of $12 \mathrm{~mm}$ in diameter (Table, 1).

Both CHX solutions $(0.12 \%$ and $0.2 \%$ ) showed approximately the same activity on the Candida albicans isolate tested (13mm and $12 \mathrm{~mm}$ respectively) when compared with the aqueous GSE as shown in Figure (1), Table (1). 


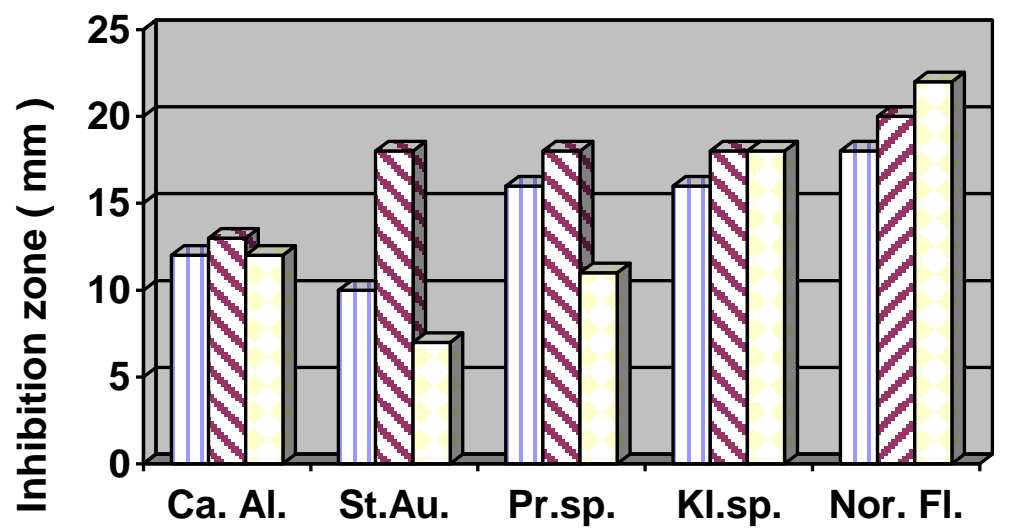

$\square$ GSE (20\%) $\square$ CHX (0.2\%) $\square \mathrm{CHX} \mathrm{(0.12 \% )}$

Figure (1): Comparison between the effect of $20 \%$ aqueous GSE and CHX solutions( $0.2 \%$ \& $0.12 \%$ ) on different types of microorganisms.

Table (1): Comparisons between the antimicrobial activity of the $20 \%$ aqueous GSE with CHX solutions

\begin{tabular}{cccc}
\hline \multirow{2}{*}{ Types of microorganism } & \multicolumn{3}{c}{ Inhibition Zone ( mm ) } \\
\cline { 2 - 4 } Candida albicans & 12 & 13 & CHX (0.12\%) \\
Staph. aureus & 10 & 18 & 7 \\
Proteus sp. & 16 & 18 & 11 \\
Klebsiella sp. & 16 & 18 & 18 \\
Normal flora & 18 & 20 & 22 \\
\hline
\end{tabular}

*Diameter of zone of inhibition in mm (Data represented as mean of three reading);**Disc diameter $=$ $6 \mathrm{~mm}$

\section{DISCUSSION}

In this study, solutions of $20 \%$ concentrated GSE (aqueous and ethanolic) were tested for antibacterial properties against a number of gram negative and gram positive organisms. The ethanolic extract showed no activity against all test microorganisms. This is in agreement with Adedeji et al. where negative results were also obtained. Kroum et al. found that methanolic extract were more active than ethanolic extract, but many studies showed that ethanolic GSE possess good antibacterial activities against many types of mi-

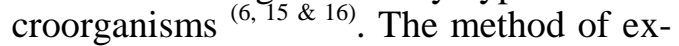
traction will influence the chemical composition, and thus, can have repercussion regarding their biological properties ${ }^{(17) .}$ Techniques of solubility of these substances are among other problems. Normalization of methods and laboratory conditions, in addition to the techniques used (extraction، dissolution and dispersion, culture medium) for testing biological and pharmacological activities of solutions at the definitive stage of laboratory screening are desirable, in order to provide a common basis for the comparison of results obtained in various parts of the world in different organisms tested under similar laboratory conditions.

The aqueous GSE has consistently good antimicrobial activity against all biotype tested. This is comparable to that of 
proven topical antibacterial solutions (CHX). These results are also in agreement with several scientific studies which showed that GSE possess good antibacterial activities against many types of microorganisms ${ }^{(5,6 \& 15)}$. Chemical research revealed the presence of flavonoids, ascorbic acid, tocopherols, citric acid, limonoids, sterols and minerals in grapefruit seeds and pulp extracts ${ }^{(4,5 \& 16)}$. This beneficial antibacterial effect of GSE has been attributed to the antioxidant activity of citrus flavonoids, such as naringenin and hesperidine ${ }^{(4)}$. The presences of those compounds were confirmed by thin layer chromatography ${ }^{(5)}$. Heggers et al. with aid of scanning transmission electron microscopy revealed GSE's antibacterial activity. It was evident that GSE disrupts the bacterial membrane and liberate the cytoplasmic contents with in 15 minutes after contact even at more diluted concentration ${ }^{(7)}$.

Fungi or yeast constitute a small proportion of the usual oral microbiota with Candida species being the most common of the fungi present in healthy $(30-45 \%)$ individual. Aqueous CHX solution has a wide spectrum of antimicrobial activity at low concentrations and is especially effective against Candida albicans ${ }^{(11)}$ and this is in agreement of our result were both CHX preparations had more or less same antifungal activity and this was comparable with that of our preparations.

Krajewska et al. found that 33\% $(\mathrm{m} / \mathrm{V})$ GSE concentration exert a potent antifungal activity against the yeast like fungi strains and had low activity against germatophytes and moulds (18), while Cvetnić and Vladimir - Kneźević reported that GSE exhibit antifungal activity against all tested strains of Candida albicans in concentrations from $8.25 \%$ to $16.50 \%(\mathrm{~m} / \mathrm{V})$ (inhibition zones ranging from $9 \mathrm{~mm}$ to $11 \mathrm{~mm})^{(5)}$ and this is in agreement of our result.

The inhibitory action of these natural products on mould could involve cytoplasmic membrane granulation, rupture and inactivation and / or inhibition of intercellular and extracellular enzymes. These biological events could take place separately or concomitantly culminating with mycelium germination inhibition ${ }^{(19)}$. Brull and Coote reported that plant lytic enzymes act on fungal cell wall causing breakage of $\beta-1,3$ glycan, $\beta-1,6$ glycan and chitin polymers which could be the cause of death in those fungal strains ${ }^{(20)}$.

Despite the fact that $\mathrm{CHX}$ were found to be superior to the tested aqueous extract, the latter showed slight, but constant activity against all the tested bacteria and yeast.

\section{CONCLUSIONS}

The use of $20 \%$ concentration of GSE aqueous solution has effective anti bacterial activities against Staphylococcus aureus, Proteus vulgaris, Klebsiella pneumonia, Candida albicans and normal mouth flora. The antibacterial activity of some of that extracts was of such a level that it would probably be therapeutically useful, because its activity was comparable with one of most widely used antiseptic solution.

\section{REFERENCES}

1. Barnes J, Anderson LA, Pillipson JD. Herbal medicines. A guide for healthcare professionals. 2nd edition, Pharmaceutical Press, London. 2002. P. 3.

2. Majorie M. Plants Products as antimicrobial agents. Clini Micro Rev. 1999; 12: 564 582.

3. Hammer KA, Carson CF, Riley TV. Antimicrobial activity of essential oils and other plant extracts. J Applied Microb. 1999; 86: 985 - 990.

4. Dembinski A, Warzecha Z, Konturek SJ, Ceranowicz P, Dembinski M, Pawlik WW, Kusnierz - Cabala B, Naskalski JW. Extract of grapefruit seed reduces acute pancreatitis induced by ischemia / reperfusion in rat; possible implantation of tissue antioxidants. J Physiol Pharmacol. 2004; 55(4): $811-821$.

5. Cvetnić Z, Vladimir - Kneźević S. Antimicrobial activity of grapefruit seed and pulp ethanolic extract. Acta Pharm. 2004; 54: $243-250$.

6. Reagor L, Gusman J, McCoy L, Carino E, Heggers JP. The effectiveness of processed grapefruit seed extract as antibacterial agent: 1. An in vitro agar assay. J Altern Complement Med. 2002; 8: 325 - 332.

7. Heggers JP, Cottingham J, Gusman J, Reagor L, McCoy L, Carino E, Cox R, Zhao J. The effectiveness of processed grapefruit seed extract as an antibacterial agent: II. Mechanism of action and in vitro toxicity. J Altern Complement Med. 2002; 8: $333-340$.

8. Adedeji GB, Fagade OE, Oyelade AA. prevalence of Pseudomonas aeruginosa in 
clinical samples and its sensitivity to citrus extract. African J Bio Res. 2007; 10:183187.

9. Al-Joboory A, Al-Rawi M. Natural pharmacology. 1st ed. Baghdad: dar Al-Huriah; 1994.

10.AL- Nouman AY. Effect some plants extracts on the growth and metabolism of gram positive and gram negative bacteria. $\mathrm{Ph}$ thesis. College of Science, Mosul University. 1998.

11.Siqueira JF Jr, Rocas IN, Paiva SS, Guimaraes-Pinto T, Magalhaes KM, Lima KC. Bacteriologic investigation of the effects of sodium hypochlorite and chlorhexidine during the endodontic treatment of teeth with apical periodontitis. Oral Sur, Oral Med, Oral Pathol, Oral Radiol and Endo. 2007; 104: 122-130.

12.Pre Scott LM, Harley JP, Klein DA. Micro biology. 3rd ed. Wm C Brown communication, Inc., Iowa, USA; 1996.

13. Vandepitte J, Enghack K, Piot P, Heuch C. Basic Laboratory procedures in clinical bacteriology ( WHO ) - Genuva. 1991; pp21-38; 82-95.
14.Kroum S A, Satta D, Lalaoui K. Antimicrobial, antioxidant, cytotoxic activities and phytochemical screening of some Algerian plants. Europ J Scien Res. 2009; 31:289-295.

15. Von Woedtke Th, Schlüter B, Pflegel P, Lindequist U, Jülich WD. Aspect of the antimicrobial efficacy of grapefruit seed extract and its relation to preservative substances contained. Pharmazie. 1999; 54: $452-456$.

16. Giuseppe G, Davide B, Claudia G, Ugo L, Corrado C. Flavonoid Composition of Citrus Juices. Molecules. 2007;12: 1641-1673.

17.Lahlou M. Methods to Study the Phytochemistry and Bioactivity of Essential Oils. Phytother Res. 2004; 18: 435-448.

18.Krajewska KE, Lukaszuk C, Niczyporuk W. Antifungal activity of $33 \%$ grapefruit water glycerol solution. J Eur Acad Dermatol Venerol. 2003; 17: 486 - 487. Cowan NM. Plant products as antimicrobial agents. Clin Micro Rev. 1999; 12:564-582.

19. Brull S, Coote P. Preservative agents in foods: mode of action and microbial resistance mechanisms. Inter $\mathrm{J}$ Food $\mathrm{Mi}$ cro.1999; 50:1-17. 